\title{
El nacimiento del paradigma indiciario entre las ciencias y sus impases: Freud y el ejercicio investigativo basado en la lectura de indicios.
}

\author{
The birth of the indiciary paradigm between science and its \\ deadlocks: Freud and the investigative exercise based on the reading of \\ clues.
}

Jeyson Ariel Ramirez Cortés*

Resumen: En estas páginas se expondrá la forma particular en que Freud hizo uso de un método investigativo alternativo para el abordaje de múltiples fragmentos de la realidad psíquica. El método o paradigma que se desarrollará es el paradigma indiciario, un cuerpo de prácticas investigativas que nacen en los albores de la Modernidad y que brindan otro marco desde el cual acceder a una forma particular de saber del sujeto con la verdad. Si bien su aplicación puede apreciarse en otros campos de saber, cobrará particular énfasis en el uso que Freud le otorgó por su función clínica, teórica e investigativa de las formaciones del inconsciente. De esta manera, se intentará situar al psicoanálisis entre las prácticas y saberes de Occidente por la naturaleza de su método, en oposición al discurso hegemónico de las ciencias, la cual parece exigir un método unívoco y exclusivo para quien desee hacer parte de su discurso. En consecuencia, se harán evidentes las lagunas que encierra este último, el cual ha demostrado lo falible que puede resultar en su ilusión por una verdad última.

Palabras clave: método indiciario, ciencia, paradigma, epistemología, psicoanálisis.

\footnotetext{
* Investigador de la línea clínica y subjetividad del Grupo de investigación en psicología, filosofía y literatura "Agalma” de la Universidad del Valle (Cali, Colombia) Dirección electrónica: jeiar11@,hotmail.com ORCID: https://orcid.org/0000-00030038-3761. El autor quiere agradecer a John James Gómez Gallego por su enseñanza y gran influencia; por sus clases y seminarios alrededor del psicoanálisis y la investigación que permearon el presente escrito. Y al grupo de investigación Agalma que ha posibilitado las discusiones que se cuecen en su interior y de las cuales deriva una parte importante del trabajo.
} 


\begin{abstract}
In these pages, the particular way in which Freud made use of an alternative investigative method to approach multiple fragments of psychic reality will be exposed. The method or paradigm that will be developed is the indiciary paradigm, a body of investigative practices that were born at the dawn of Modernity and that provide another framework from which to access a particular way of knowing the subject with the truth. Although its application can be appreciated in other fields of knowledge, it will take particular emphasis on the use that Freud gave it for its clinical, theoretical and investigative function of the formations of the unconscious. In this way, an attempt will be made to place psychoanalysis among the practices and knowledge of the West by the nature of its method, in opposition to the hegemonic discourse of the sciences, which seems to require a univocal and exclusive method for those who wish to be part of their discourse. Consequently, the gaps in the latter will become evident, which has shown how fallible it can be in its illusion for an ultimate truth.
\end{abstract}

Key words: indiciary method, science, paradigm, epistemology, psychoanalysis.

Vosotros, señores criticos, o como quiera que os llaméis, sentís vergüenza o temor frente a ese delirio momentáneo, pasajero, que sobreviene a todos los creadores genuinos y cuya duración mayor o menor distingue al artista pensante del soñador. De abi vuestras quejas de infecundidad, porque desestimáis demasiado pronto y espigáis con excesivo rigor (carta de Schiller a Körner del $1^{\circ}$ de diciembre de 1788).

\title{
Introducción
}

La academia y, con ella, las ciencias, se empeñaron por mucho tiempo en sostener que sólo podía existir una metodología de la investigación y que el uso de tal método definía el quehacer científico. De esta manera, el uso adecuado y unívoco del mismo, aplicado a un fenómeno, estudio, o hecho, producía una forma de saber estricto, y, por ello mismo, válido y objetivo. 
Así, un cuerpo de conocimientos, para que hoy sea considerado como "científico", debe seguir, necesariamente, cierto procedimiento, ciertos pasos. Si una investigación -cualquiera que esta sea- omite o elude alguno de ellos (los cuales son establecidos por la comunidad científica), pierde inmediatamente su pretensión de cientificidad. ${ }^{1}$

De acuerdo con esto, el grado de validez de un estudio dependerá de qué tan acertado fue el investigador al momento de cumplir con los pasos. Sin embargo, como lo veremos a continuación, y tal como que nos lo muestran Freud, Morelli y Conan Doyle, entre otros, el método hegemónico junto con sus pretensiones, aun en la actualidad, puede resultar falible. Por ello es necesario que surjan otras formas de abordaje investigativo.

En este caso, el estudio sobre el que se enmarca nuestro trabajo es sobre el método o paradigma indiciario, método del cual se apropia Freud para su investigación y que es, al mismo tiempo, uno de los métodos que abren la puerta a la singularidad que reviste todo acontecimiento. Así, nuestra tesis consiste en demostrar los alcances y efectos de este método que aun en la actualidad demanda revisión y resulta importante. Por esa vía, inicialmente se hará explícito el método o paradigma indiciario junto con sus antecedentes; posteriormente nos ocuparemos del uso y valor que tuvo para Freud en un momento histórico en el que reinaba el positivismo fisiológico; y, finalmente, se propondrá una aproximación para ubicar el psicoanálisis en relación con la ciencia y cuerpos de saber derivados. Por lo tanto, la problemática que atraviesa el presente escrito se sitúa en la posibilidad de circunscribir al psicoanálisis dentro de una metodología propia de su práctica y teoría, dilucidando así el lugar que ocupa entre los saberes y prácticas de Occidente. Se trata, claro está, de una lectura epistemológica sujeta a discusión, por medio de la cual se incita al cuestionamiento de la posición del psicoanálisis y de las ciencias en general.

\section{Un paradigma naciente entre las grietas de la modernidad}

\footnotetext{
1 Pardo, Rubén, "Verdad e historicidad. El conocimiento científico y sus fracturas", en E. Díaz (Ed.), La posciencia: el conocimiento científico en las postrimerías de la modernidad, Buenos Aires, Biblos, 2007, p. 40.
} 
Quien ha otorgado el nombre de "indiciario" al método del que nos ocupamos en el presente trabajo es el historiador Carlo Ginzburg. Ginzburg sostiene que "a finales del siglo diecinueve, surgió silenciosamente, en el ámbito de las ciencias sociales, un modelo epistemológico (o, si se prefiere, un paradigma)". ${ }^{2}$ Silenciosamente, porque, como veremos, varias figuras conocidas, empezaron a hacer uso de él sin una atribución propia y explícita.

Carlo Ginzburg inicia su contextualización trayendo a colación los artículos publicados entre 1874 y 1876 en Italia por un estudioso desconocido llamado Iván Lermolieff. Posteriormente, será el crítico de arte Giovanni Morelli quien se atribuirá la autoría de aquellos trabajos, por lo cual el pseudónimo utilizado, "Iván Lermolieff", sería poco más que un anagrama. En esos trabajos, Morelli exponía al principio la forma tradicional de distinguir una obra original de una copia, a saber, mediante la identificación de las características más evidentes de cada pintor, como, por ejemplo, los ojos alzados al cielo de los personajes de Perugino, la sonrisa de los personajes de Leonardo, y así por el estilo.

Sin embargo, este método tenía un defecto y es que, sabiendo los rasgos más prominentes de las obras de cada autor, éstas eran más fácilmente imitables. Por el contrario, el método que propone Morelli es: “( ...) examinar los detalles menos trascendentes, y menos influidos por las características de la escuela pictórica a la que el pintor pertenecía: los lóbulos de las orejas, las uñas, la forma de los dedos de manos y pies". 3

Así, vemos la diferencia tajante respecto del primer método, donde la importancia estaba puesta sobre los rasgos más prominentes de cada autor. Ahora, lo trascendental se encontrará en los detalles que para los demás resultan imperceptibles y por lo tanto les pasan desapercibidos. Es ahí donde los copistas dejaban de prestar atención y se centraban en el conjunto de la obra o en los rasgos sobresalientes; sin embargo, aquellos rasgos que pasaban por alto se convertían en los más propios del autor original. Así, las características de una oreja, la forma de un dedo, de una uña, son rastros, huellas, indicios, que le servían a Morelli para atribuir la originalidad de una obra a un pintor determinado y mostrar la falsedad de otras tantas. En este sentido sobresale una afirmación de Morelli frente a la crítica tradicional: “a la

2 Ginzburg, Carlo, Mitos, emblemas e indicios, Barcelona, Gedisa, 1989, p. 138.

${ }^{3}$ Ibid., p. 139. 
personalidad hay que buscarla allí donde el esfuerzo personal es menos intenso".

Otro de los autores que Carlo Ginzburg recupera para exponer lo que a finales de siglo XIX se instauraba como un método proliferante, fue Arthur Conan Doyle, quien, por medio de Sherlock Holmes, dejó entrever su admiración por el método de Morelli. En La aventura de la caja de cartón, Holmes hace su aparición:

No ignorará usted, Watson, en su condición de médico, que no hay parte alguna del cuerpo humano que presente mayores variantes que una oreja. Cada oreja posee características propias, y se diferencia de todas las demás. En la "Reseña antropológica" del año pasado, encontrará usted dos breves monografías sobre este tema, que son obra de mi pluma. De modo que examiné las orejas que venían en la caja con ojos de experto, y registré cuidadosamente sus características anatómicas. Imagínese cuál no sería mi sorpresa cuando, al detener mi mirada en la señorita Cushing, observé que su oreja correspondía en forma exacta a la oreja femenina que acababa de examinar. No era posible pensar en una coincidencia. En ambas existía el mismo acortamiento del pabellón, la misma amplia curva del lóbulo superior, igual circunvolución del cartílago interno. En todos los puntos esenciales se trataba de la misma oreja. Desde luego, enseguida comprendí la enorme importancia de semejante observación. Era evidente que la víctima debía ser una consanguínea, probablemente muy estrecha de la señorita (...)". ${ }^{4}$

Es conocida la perspicacia de Sherlock Holmes o de su predecesor, Dupin, personaje de Edgar Allan Poe a quien Conan Doyle debe la existencia de su protagonista. Ambos nos dejaron un buen ejemplo de lo que puede llegar a revelar aquello que pasa desapercibido, aquello que se presenta como carente de importancia, eso que mediante el detalle toma la forma de un rastro, de una colilla de cigarrillo, de una tuerca o de una uña. Al mismo tiempo, ambos investigadores dejan en evidencia la imposibilidad de los sistemas policiacos y sus procedimientos hegemónicos para el abordaje de los casos. En el caso de Dupin, se hace continuamente evidente:

${ }^{4}$ Ibid., p. 140. 
No debemos pensar en los modos posibles que surgen de una investigación tan rudimentaria -dijo Dupin-. La policía parisiense, tan alabada por su penetración, es muy astuta, pero nada más. No procede con método, salvo el del momento. Toma muchas disposiciones ostentosas, pero con frecuencia éstas se hallan tan mal adaptadas a su objetivo (...) Los resultados obtenidos son con frecuencia sorprendentes, pero en su mayoría se logran por simple diligencia y actividad. Cuando éstas son insuficientes, todos sus planes fracasan. ${ }^{5}$

Pues bien, lo que nos señalan estos personajes es que el método policial reduce todo caso a una metodología universal: la prefectura tiene un método que ha funcionado para la resolución mecánica y aparentemente efectiva de los casos, convirtiéndose entonces en un: "para todo $\mathrm{X}$, el procedimiento a seguir será el determinado por la prefectura". Por otro lado, está claro que la premisa universal que se configura con el procedimiento termina siendo falsa. Eso es lo que encuentra Poe en sus tres relatos donde hace aparición Dupin: "La carta robada", "Los crímenes de la calle Morgue” y "El misterio de Marie Rogêt". De ahí que la prefectura recurra con frecuencia a la ayuda de nuestro personaje, quien, mediante un método heterodoxo y el hallazgo de indicios imperceptibles al ojo común, concluye en la resolución eficaz de los casos.

Así, al margen de la metodología tradicional, y a raíz de sus impases, es que surgen otras formas de abordar un hecho, lo cual demuestra continuamente lo falible que pueden llegar a resultar los métodos hegemónicos. A continuación, se hará evidente la metodología o el paradigma que surge a causa de esos impases bajo una multiplicidad de usos y que adquiere su denominación como método indiciario, Sin embargo, ahora, su silencioso uso estará en manos de Freud.

\section{Freud y la investigación: una metodología particular basada en indicios}

5 Poe, Edgar, "Los crímenes de la calle Morgue", en Cuentos, Puerto Rico, Universidad de Puerto Rico, 1956, p. 239. 
Desde temprano, Freud fue criticado abiertamente por sus diferentes elucubraciones. Inicialmente, en 1894, por sus estudios sobre la cocaína, donde estuvo cerca de hacerse un lugar en la ciencia por el descubrimiento de la anestesia local. A contrario de lo que se cree, sus estudios no estaban enfocados en su uso recreativo como muchos detractores sostienen, sino en sus propiedades analgésicas y anestésicas para intervenciones quirúrgicas y control del dolor. Posteriormente, las críticas sobrevinieron en 1905 con la publicación de sus Tres ensayos de teoría sexual, una parte protestando contra la existencia de la sexualidad infantil, y, la otra, desaprobando que los homosexuales fueran personas normales pues consideraban que su anormalidad era genésica y debía ser corregida. ${ }^{6}$ Igualmente, sus desarrollos sobre el complejo de Edipo, la castración y demás intentos de explicar las vicisitudes constituyentes de la subjetividad humana fueron presa del juicio cientificista.

Sin embargo, para acercarnos a la teoría freudiana, es imperativo conocer el proceder de su artífice, permitiéndonos comprender que su metodología surge de la singularidad de eso que a simple vista denota un sin sentido, de eso que se repite y que se manifiesta en la cotidianidad. Eso para lo cual el sueño positivista se queda a medio decir y no tiene explicación más que provisoria. De antemano, cabe recordar que desde temprano Freud conoció bastante bien la obra de Morelli:

Mucho antes de que pudiera enterarme de la existencia del psicoanálisis, supe que un conocedor ruso en materia de arte, Iván Lermolieff, había provocado una revolución en los museos de Europa revisando la autoría de muchos cuadros, enseñando a distinguir con seguridad las copias de los originales y especulando sobre la individualidad de nuevos artistas, creadores de las obras cuya supuesta autoría demostró ser falsa. ${ }^{7}$

${ }^{6}$ Recordemos que esta concepción se mantuvo hasta la tercera edición revisada del Manual Diagnóstico y Estadístico de Trastornos Mentales de la Asociación Psiquiátrica Americana (1988).

${ }^{7}$ Freud, Sigmund, El Moisés de Miguel Ángel, en Obras completas, edición de J. Strachey, traducción de J. L. Etcheverry y L. Wolfson, Vol. XIII, Buenos Aires, Amorrortu, 1986, p 227. 
Empezaremos entonces haciendo evidente la metodología usada por Freud en la interpretación de los sueños, cometido que para la ciencia estricta carecía de sentido y significación, ya que su explicación quedaba relegada a la de un proceso somático. Pues bien, lo que encuentra Freud es que, más allá del componente somático que se vea involucrado, es un acto en pleno derecho psíquico y dotado de significado. Su hipótesis no es caprichosa, sino que se nutre de una multiplicidad de fuentes científicas y filosóficas en las que se debatían múltiples aspectos del sueño y su sentido.

En este contexto, Freud traza un recorrido acerca de la forma en que se han venido tratando a los sueños desde los inicios de la cultura occidental. Encuentra dos métodos para su interpretación. El primero de éstos es el método simbólico, el cual consiste en tomar todo el contenido onírico del sueño y sustituirlo por otro contenido que sea comprensible. ${ }^{8}$ El ejemplo paradigmático aquí es el sueño del Faraón de las escrituras bíblicas. El Faraón relata que en su sueño observa 7 vacas gordas paseándose por la pradera, seguidamente aparecen otras 7 vacas, en este caso, flacas y enjutas que se comerían a las gordas. José interpreta el sueño anunciando que lo que espera en el reino es que después de 7 años de abundancia, sobrevengan 7 años de escasez que consumirían las riquezas obtenidas durante ese periodo. Así, lo que hace es interpretar el sueño en su conjunto reemplazando sus elementos por una serie de representaciones comprensibles.

El segundo método, el método del descifrado, considera al sueño como una suerte de escritura cifrada en que cada signo ha de traducirse, merced a una clave fija, en otro de significado conocido. Entonces, de lo que se trata es de sustituir elementos cifrados en el sueño por atribuciones que le puedan brindar un sentido. Sin embargo, la forma en que se realizaba tal cometido en la época de Freud y en los tiempos precedentes, era mediante un "libro de sueños" que asignaba a cada elemento del sueño, un significado. Por ejemplo, si la persona soñaba con cartas, el libro le decía el significado que le correspondía, además de posibles tintes premonitorios y adivinatorios que podían llegar a contener respecto de un posible mensaje del porvenir. Al respecto, Freud hace una observación muy precisa: "Pero he aquí lo esencial

\footnotetext{
${ }^{8}$ Freud, Sigmund, La interpretación de los sueños. Primera parte, en Obras completas, edición de J. Strachey, traducción de J. L. Etcheverry y L. Wolfson, Vol. IV, Buenos Aires, Amorrortu, 1979.
} 
de ese procedimiento: el trabajo de interpretación no se dirige a la totalidad del sueño, sino a cada uno de sus fragmentos por sí, como si el sueño fuera un conglomerado cada uno de cuyos bloques constitutivos reclamase una destinación particular".?

Como vemos, a primera vista Freud desecha el uso de un manual que pueda dar cuenta del significado pleno de la lógica de las representaciones sobrevenidas en el paciente. Recordemos que conocía muy bien las contingencias del lenguaje a través de las representaciones-palabra (que abordaremos más adelante), y las representaciones-cosa. Sin embargo, en su interés sobresale expresamente lo que desea retomar, señalando que su método se aproxima más al de descifrado, puesto que, como éste, es una interpretación en détail y no en masse; es así como el paciente aprehende de antemano el sueño como algo compuesto, como un conglomerado de formaciones psíquicas.

Por lo tanto, vemos la importancia que tiene el detalle, pudiéndose comprender éste como la menor parte o el fragmento. Así, la interpretación dependerá de la producción que haga el paciente, a partir de las representaciones, de los fragmentos que sobrevengan en su relato del sueño, pudiendo encontrar un sentido allí donde lo "carente de importancia" parecía oscuro y sin sentido. Precisamente en el sueño, ahí donde el yo deja de prestar atención, de controlar su pensamiento, se levantan las resistencias y aparece algo de eso que en estado de vigilia pudo resultar insoportable para él. Tal es el valor de estos fragmentos, detalles, huellas y rastros que, advierte Freud, pasan desapercibidos, pero que para el psicoanálisis desbordan de sentido: "No se atribuye valor solamente, como en la vigilia, a lo más significativo, sino también a lo más indiferente, a lo más insignificante del recuerdo". ${ }^{10}$

Ahora resulta evidente la alusión inicial a Morelli y su método. Vemos cómo en los resquicios de la metodología usada por Freud en los sueños deja entrever lo fiel que fue a la obra del crítico de arte. Sin embargo, no es hasta 1914 que reconocerá su importancia para el psicoanálisis: "Luego me interesó mucho saber que bajo ese seudónimo ruso se ocultaba un médico italiano de apellido Morelli. Falleció en 1891 siendo senador del Reino de Italia. Creo

\footnotetext{
9 Ibid., p. 120.

${ }^{10}$ Ibid., p. 44.
} 
que su procedimiento está muy emparentado con la técnica del psicoanálisis médico". 11

Ahora bien, en la medida en que se ha estado haciendo uso del término "representación", cabe desarrollar su lógica con miras a una comprensión de las implicaciones que tenía para Freud el lenguaje desde sus inicios. En efecto, no es gratuito que Freud haya seleccionado el término Vorstellung ("representación") para destacar su importancia y diferenciarlo fundamentalmente de la huella mnémica. La huella era simplemente una marca que quedaba de la vivencia satisfacción-insatisfacción, pero que, a falta de conexión con el objeto primordial, la única referencia que tenía era a sí misma. Dicho de otra manera, la huella indicaba simplemente un resto de carácter autorreferencial. La representación, en cambio, tiene la facultad de remitir a otras representaciones.

¿Lo que no se puede elaborar, lo que no se puede integrar al psiquismo es no representado o no inscripto? Representado, ¿para quién? El problema es que siempre se parte de lo irrepresentable para el yo, no de lo irrepresentable para el psiquismo. Es el sujeto quien no se lo puede representar, porque, es indudable, faltan significantes. Lo irrepresentable es aquello que no puede ser, de alguna manera, transcripto. La pregunta es si esto irrepresentable está inscripto de alguna manera, aun cuando no tenga transcripción. ${ }^{12}$

Eso no es irrepresentable para el psiquismo porque precisamente la condición del sistema mnémico es que permite su inscripción en tanto alteración. Cabe recordar que Freud consideraba la huella mnémica una alteración del sistema, que quedaba como permanente en tanto lo que la había producido era momentáneo. Por lo tanto, lo irrepresentable, gracias al sistema mnémico del psiquismo, puede ser inscrito y almacenado a manera de huella. Así, esta última simplemente dio cuenta de algo que se había inscrito y que lo efímero del objeto dejaba como resto. "Yo he señalado muchas veces que las primeras inscripciones no son simbólicas en sentido estricto, porque no

${ }^{11}$ Freud, S., El Moisés de Miguel Ángel, p. 227.

${ }^{12}$ Bleichmar, Silvia, La construcción del sujeto ético, Buenos Aires, Paidós, p. 152. 
remiten a nada más que a sí mismas. Y lo simbólico siempre implica la relación entre dos elementos". ${ }^{13}$

De tal forma, el carácter no simbólico de estas huellas que constituyen inicialmente el aparato psíquico es dado como antecedente del lenguaje. Son huellas que, en tanto no se posee lenguaje, quedan por fuera de su registro. $\mathrm{O}$ lo que es lo mismo: no hay una representación de algo para algo. El objeto que efectuó su registro sólo bastó para inscribirlas y fundar el antecedente de la futura simbolización, pero, por ahora, la pérdida del objeto las hace simplemente autorreferenciales.

Ahora bien, eso no dice nada al yo. Éste se percata de algo de esas inscripciones cuando la huella deviene accesible para el sistema preconsciente-consciente mediante su enlace con una representación, lo cual va a constituir, en última instancia, la esencia de la representación, lograda mediante la investidura de la huella mnémica. Freud lo establece concluyendo que "toda la diferencia estriba en que las representaciones son investiduras en el fondo- de huellas mnémicas...". ${ }^{14} \mathrm{O}$ como lo afirmaba en su primera teorización, ${ }^{15}$ la huella debía ser sometida a retranscripción. Así, se evidencia la condición para que la lógica del lenguaje introduzca al sujeto en la trama de lo simbólico, a saber, la remisión a un segundo elemento. De esta forma, una huella o representación alguna devienen simbolizables a causa de un Otro elemento: "Las llamamos simbolizadas, simbolizables, cuando logran trascripción. De manera que para que hablemos de simbolización no alcanza con que haya inscripción, es necesario que haya retranscripción". ${ }^{16}$ Como se mencionó anteriormente, las peripecias del lenguaje se hacen evidentes por

\footnotetext{
13 Ibid., p. 153.

14 Freud, Sigmund, "Lo inconsciente", en Obras completas, edición de J. Strachey, traducción de J. L. Etcheverry y L. Wolfson, Vol. XIV, Buenos Aires, Amorrortu, 1984, p. 174.

15 Me refiero a lo propuesto por Freud en la Carta 52 a Fliess del 6 de diciembre de 1896: "Tú sabes que trabajo con el supuesto de que nuestro mecanismo psíquico se ha generado por estratificación sucesiva, pues de tiempo en tiempo el material preexistente de huellas mnémicas experimenta un reordenamiento según nuevos nexos, una retrascripción [Umschrift]" (Freud, Sigmund, Fragmentos de la correspondencia con Fliess, en Obras completas edición de J. Strachey, traducción de J. L. Etcheverry y L. Wolfson, Vol. I, Buenos Aires: Amorrortu, 1986, p. 274).

${ }^{16}$ Bleichmar, S., op. cit., p. 153.
} 
esta vía, en la cual la representación tampoco implica el objeto, simplemente a lo que se anuda es a otra transcripción, a otra representación ${ }^{17}$. Eso mismo es lo que hace que no haya una ley de transcripción, sino que ésta se funde en el carácter desplazatorio de las palabras, es decir, contingentemente una a otra, así hasta configurar esa imagen ilusoria denominada yo: "Prc (preconciencia) es la tercera retrascripción, ligada a representaciones-palabra, correspondiente a nuestro yo oficial". ${ }^{18}$ Estas elucidaciones son muy tempranas en la obra de Freud, pero no disruptivas en relación con lo que posteriormente será su investigación bajo el nombre de psicoanálisis. De hecho, lo que iba encontrando es que tanto la subjetividad como la realidad se fundan bajo el efecto de las palabras.

Habiéndonos detenido un momento a examinar lo que Freud comprendía como lenguaje, podemos remitirnos a otra de las formaciones que fue objeto de su interés: los actos fallidos. Al respecto, dice: "Escogeremos ciertos fenómenos que son muy frecuentes, harto conocidos y muy poco apreciados, y que nada tienen que ver con enfermedades puesto que pueden observarse en cualquier persona sana". ${ }^{19}$ Efectivamente, lo que encuentra Freud es el valor, precisamente, del fragmento, de la menor parte, de la partícula lingüística que había pasado desapercibida a los ojos científicos por carecer de importancia. Del conjunto de actos fallidos que analizó Freud analizaremos un ejemplo para nuestro cometido, un caso de desliz en el habla: "Un joven interpela a una dama por la calle con estas palabras: 'Señorita, permítame que la acom-traje [begleit-digen]'. Es evidente, se propuso

${ }^{17}$ Realizando los salvamentos necesarios en función de la eminente aparición del término significante, indicamos que éste comporta una lógica, no igual a la representación freudiana, pero sí con una propiedad similar: la remisión a un segundo elemento, a múltiples significados, y en última instancia, la no correspondencia entre el significante y el significado. En relación con este carácter, Masotta describe al significante de la siguiente forma: "es la palabra, en tanto la palabra es capaz de remitir a más de un significado" (Masotta, Oscar, Lecturas de psicoanálisis. Freud, Lacan, Buenos. Aires, Paidós, 1992, p. 18).

${ }^{18}$ Freud, S., Fragmentos de la correspondencia con Fliess, p. 275.

${ }^{19}$ Freud, Sigmund, Conferencias de introducción al psicoanálisis. Partes I y II, en Obras completas, edición de J. Strachey, traducción de J. L. Etcheverry y L. Wolfson Vol. XV, Buenos Aires, Amorrortu, 1978, p. 22. 
decir que le gustaría 'acompañarla' [begleiten], pero temió 'ultrajarla' [begleidigen] con su propuesta". ${ }^{20}$

Es necesario analizar este ejemplo desde el idioma en que se presentó el desliz, en este caso el alemán. La palabra que iba a ser mencionada inicialmente era begleiten (acompañar). Sin embargo, la palabra que se encontraba in-tension era begleidigen (ultrajar), provocando que, por efecto de proximidad, se condensaran ambas en el neologismo begleit-digen. Ambas palabras presentan la misma preposición "beglei", dando pistas a colegir que lo que se desliza en su aparición es "digen”.

Por otro lado, más allá del significado que pueda contener el ejemplo y lo que se pueda pensar con respecto a un posible deseo del joven, el pasaje se propone llamar la atención sobre la condensación de la palabra a partir de la conservación u ocupación de una partícula lingüística, a saber, la letra, y lo que pueden llegar a fundar si se sigue su lógica significante. Lacan, por ejemplo, brindó un estatuto especial a la construcción freudiana de las posibilidades significantes en que discurre el sujeto. En el transcurso de su vida, le prestó particular atención a la materialidad que suponía el significante: "Que no sean palabras a la deriva, es decir, que su deriva sólo esté sujeta a una ley de las palabras -a una lógica radical que intento establecer- es algo que lleva a una revisión total de todo cuanto ha podido pensarse hasta ahora del pensamiento". ${ }^{21}$

Lo que articula precisamente Lacan bajo el significante se encuentra supeditado a los andamiajes de la cadena significante, de la causalidad psíquica, como ordenante del discurso y acto del sujeto. En ese sentido, en esa banalidad que puede resultar un desliz en sus diferentes modalidades, un olvido, y demás, existe una lógica que no es para nada casual desde lo que implica el lenguaje como estructurante del inconsciente. Hasta 1901,22 esto simplemente había quedado velado para la ciencia, casi nadie le prestaba atención al equívoco o las diferentes modalidades del desliz: trastrabarse en el

${ }^{20}$ Freud, Sigmund, Psicopatología de la vida cotidiana, en Obras completas, edición de J. Strachey, traducción J. L. Etcheverry y L. Wolfson, Vol. VI, Buenos Aires, Amorrortu, 1986, p. 70.

${ }^{21}$ Lacan, Jacques, "Breve discurso en la ORTF", en Intervenciones y textos 2, Buenos Aires, Manantial, 1988 [1966], p. 37.

22 Año en que aparece Psicopatología de la vida cotidiana 
habla, la lectura, la escritura y la escucha. Y si se le hubiese prestado atención, tal fenomenología hubiese quedado relegada a un intento de explicación orgánica, siempre incompleta, tal y como ocurrió con la teoría hegemónica del sueño, donde los detalles que provienen del inconsciente, tanto en éste como en las otras formaciones, fueron pasados por alto. Por lo tanto, la investigación que Freud emprendió no solo residió en la utilización del método, sino también en la adopción de un objeto que era franqueable por esta vía, pero ajeno de las ciencias y soslayado por Occidente, a saber, la existencia de actos anímicos inconscientes: "La obstinada negativa a admitir el carácter psíquico de los actos anímicos latentes se explica por el hecho de que la mayoría de los fenómenos en cuestión no pasaron a ser objeto de estudio fuera del psicoanálisis". ${ }^{23}$

En resumen: ya sea en el lugar de un sueño, un acto fallido, un lapsus, una fantasía o un síntoma, las formaciones del inconsciente sirven a Freud para rastrear el material de cada una de ellas. Esta pesquisa de formaciones del inconsciente, que toman un lugar imperante en la lectura de indicios, como método, habilita una posibilidad de prescindir de los universales pasos del unívoco quehacer científico. Es lo singular que revista en cada caso, en cambio, lo que encuentra su lugar en la clínica psicoanalítica, ya que, como es causado, el destinatario para cada interpretación, debido a lo que comporta el hecho de que el material parte de su propio inconsciente, es el propio sujeto. Ante la eventual aparición de cada formación del inconsciente, Freud iba haciendo evidente su método, o más bien, el que tomaba su paciente, aplicándolo, dejando en evidencia que la clínica de la escucha se muda continuamente en una clínica de la lectura, teniendo el material inconsciente como texto latente a descifrar en la lectura de sus indicios.

Es en este punto donde encontramos el impase epistemológico que lleva a la disyunción entre la ciencia y el psicoanálisis, justamente donde procederemos a situar la tensión que tiene lugar dentro del compendio de saberes y prácticas de Occidente que implican la relación del sujeto con la verdad.

${ }^{23}$ Freud, Sigmund, Lo inconsciente, en Obras completas, edición de J. Strachey, traducción de J. L. Etcheverry y L. Wolfson, Vol. XIV, Buenos Aires, Amorrortu, 1984, p. 165. 


\section{¿Ciencia o no? La emergencia epistemológica del psicoanálisis en Occidente.}

Actualmente las críticas a la teoría freudiana son, en su mayoría, por su metodología. Se la considera, en efecto, como una pseudociencia anacrónica en su práctica, en la medida en que no está avalada por el método de las ciencias exactas, método que, junto con sus derivados estadísticocuantificables, compruebe sus premisas y eficiencia. Sin embargo, su metodología no obedece, ni tiene la intención de obedecer al ideal, siempre ilusorio, de la universalidad. Esto es lo que Freud deja entrever desde temprano en la proton pseudos, apartado del proyecto de psicología para neurólogos, anunciando la falsedad de toda premisa mayor. Así, su método no forma parte del de las ciencias que, más que ser rigurosas, son rígidas en su ilusión de una posible universalización, ajustando todo objeto de estudio a una metodología fija de investigación. Y aun después de los avances de la física moderna con el principio de incertidumbre y la relatividad especial, la derrota de toda predictibilidad estadística por medio de las teorías derivadas del caos, de la lógica y la matemática con el teorema de incompletitud de Gödel y la singularidad matemática; aun después de todo ello, hay quienes continúan abogando por la capacidad metodológica infalible de la ciencia. Es cierto, también han surgido científicos, como, por ejemplo, Ilya Prigogine, físico, Premio Nobel de Química, que exhibieron el acto irrisorio de la ilusión humana por un saber final. Prigogine, en efecto, en su libro El fin de las certidumbres, pone en evidencia la limitación de las ciencias duras en orden a una aprehensión y explicación última de la naturaleza. Por el contrario, dice, la incertidumbre no sólo se hace inherente al entendimiento humano, sino también a la realidad: "el hombre se defiende de la noción de ser un objeto impotente en el curso del universo". ${ }^{24}$ Eventualmente, como efecto, la resistencia humana hacia tal asimilación es su defensa por continuar con el delirio antropocéntrico. Sin embargo, al producto científico no le queda más que ser una verdad incompleta, provisoria y pasible de ser falseada.

\footnotetext{
${ }^{24}$ Prigogine, Ilya, El fin de las certidumbres, Santiago, Editorial Andrés Bello, p. 8.
} 
Como pudimos ver, el psicoanálisis surge habilitando un tipo de práctica y saber derivado de la lectura de indicios, de formaciones del inconsciente, $\mathrm{y}$, al mismo tiempo, habilitando un tipo determinado de relación del sujeto con la verdad. En ese sentido, cabe recordar la singularidad que debía afrontar la técnica psicoanalítica para Lacan, tópico que dominó enteramente su atención en los primeros seminarios:

Insisto en el hecho de que Freud avanzaba en una investigación que no está marcada con el mismo estilo que las otras investigaciones científicas. Su campo es la verdad del sujeto. La investigación de la verdad no puede reducirse enteramente a la investigación objetiva, e incluso objetivamente, del método científico habitual. ${ }^{25}$

Así, el valor que tenía la verdad tanto para Freud como para Lacan se encontraba en el terreno de la verdad que le concierne a cada sujeto, una verdad siempre a medio decir, y que, para ello, el método, tal y como se ha estado desarrollando, no podía ser el científico. Al contrario, este método se encontraba, por la naturaleza con que se había concebido, impedido para dar cuenta de algo de esa verdad. Dicho de otra manera, esa verdad sólo es posible en el seno de las vicisitudes del lenguaje posibilitadas por la investigación psicoanalítica a partir de la representación-palabra, del significante, y en general, del lenguaje humano, tal como se expuso en su propiedad de remisión a un segundo elemento. En este sentido, Freud, junto con Nietzsche y Marx, habían señalado un punto de ruptura, modificando el estatuto del lenguaje frente al sujeto y la verdad como una forma particular de interpretación. Así lo dice Foucault:

En todo caso, y es a este propósito que querría hacer algunas sugerencias, me parece que Marx, Nietzsche y Freud no han multiplicado, en manera alguna, los signos en el mundo occidental. No han dado un sentido nuevo a las cosas que no tenían sentido. Ellos han cambiado, en realidad, la

${ }^{25}$ Lacan, Jacques El seminario. Libro 1: Los escritos técnicos de Freud, Buenos Aires, Paidós, 1981 [1953], p. 40. 
naturaleza del signo, y modificado la manera como el signo en general podía ser interpretado. ${ }^{26}$

Es justamente por esto último que al cientificismo, en su delirio anacrónico de generalización, le resulta difícil aceptar la introducción del psicoanálisis en el mundo científico. En primera instancia, porque su metodología no implica una explicación universal de los hechos o una validez última, ya que, paradójicamente, al igual que en la ciencia, el punto de vista del investigador es el que crea aquellas. Esto ya había sido anticipado por Saussure: "Lejos de preceder el objeto al punto de vista, se diría que es el punto de vista el que crea el objeto (...)". ${ }^{27}$ Así, la verdad se encuentra relegada a la construcción de los hechos instituida por el investigador. En consecuencia, el hecho de estudio, el fenómeno, o la realidad, no son más que una creación del investigador, hasta tal punto que ha sido necesaria la presencia de otros para hacer más válidos los estudios. A esto último la epistemología lo ha denominado intersubjetividad, esto es, la necesidad de una verdad consensuada. En tal sentido, frente al estado actual del discurso científico, Vieytes sostiene:

Esos conceptos organizadores que le dan sentido y forma a nuestro mundo no son caprichosos o inherentes a cada sujeto -pura subjetividad-, sino el fruto de ciertos acuerdos o consensos sociales más o menos implícitos sobre lo que es relevante -digno de ser conceptualizado- en determinado lugar y tiempo históricos. En otras palabras, toda observación implica un acuerdo social acerca de los códigos a partir de los cuales ese segmento del mundo se torna inteligible, cognoscible y aun perceptible para esa comunidad de significado. ${ }^{28}$

26 Foucault, Michel (1964), Nietzsche, Frend, Marx. Buenos Aires, El cielo por Asalto,1964, p. 38.

27 Saussure, Ferdinand, Curso de lingüistica general, Buenos Aires, Editorial Losada, 1945, p. 36.

${ }^{28}$ Vieytes, Rut, Metodología de la investigación en organizaciones, mercado y sociedad, Buenos Aires, Editorial de las ciencias, 2004, p. 158. 
Es sobre esto que, como vemos, se ha tenido que desplazar forzosamente toda verdad última: intersubjetividad, creación de sentido, consenso académico, etc.

En segunda instancia, la dificultad de la ciencia para reconocer al psicoanálisis radica en la herida que éste le produjo a la humanidad con la conceptualización del inconsciente. Hasta entonces -huellas del cogito cartesiano-, se pretendía mantener la ilusión de que el psiquismo era uno y derivado de la razón consciente. Sin embargo, Freud se había percatado desde temprano de la aparición de grupos representacionales que no podían ser introducidos en el devenir consciente, y que su falta de integración tenía efectos sobre las personas. Había estado teorizando al respecto desde finales del siglo XIX con sus estudios de las neuropsicosis de defensa mediante la hipnosis y el método catártico bajo diferentes nombres: "grupo psíquico segundo", "grupo psíquico escindido" y "grupo psíquico separado". Ulteriormente encontrará que este complejo representacional, que creía contingente, es propio de lo humano, de la represión primaria como fundadora de lo inconsciente, y que posee unas operatorias, procesos y estructuras particulares. Precisamente, lo que termina exponiendo Freud es que lo psíquico no es una unidad, quitándole así al sujeto las llaves de su propia casa. Así, el psiquismo no es uno, sino dos, y hasta tres, ${ }^{29}$ demostrando otras propiedades de esta fragmentación. En Lo inconsciente, por ejemplo, expone las características de este sistema: "ausencia de contradicción, proceso primario (movilidad de las investiduras), carácter atemporal y sustitución de la realidad exterior por la psíquica". ${ }^{30}$

La ausencia de contradicción, por ejemplo, con el re-descubrimiento de lo inconsciente, posibilita una lógica que no forma parte de la razón consciente. Esto no significa que sea irracional, sin embargo, como han mostrado tanto Freud como Lacan. Todo lo contrario, la lógica que habilita el inconsciente deviene de la lógica moderna de los siglos XIX y XX desarrollada por Bertrand Russell, Kurt Gödel, Boole y otros matemáticos. Por consiguiente, la operatividad del inconsciente se encuentra del lado de la lógica paradójica, de la exclusión del principio aristotélico de no contradicción, del no-todo, del al menos-uno, entre algunos de sus principios

\footnotetext{
${ }^{29}$ Inconsciente, preconsciente, consciente; Ello, yo y superyó.

${ }^{30}$ Freud, S., Lo inconsciente, p. 183.
} 
derivados. Ya Lacan en 1953 sostenía la importancia del re-descubrimiento de Freud de esa otra razón: "se denomina razón a la introducción de un orden de determinaciones en la existencia humana, en el orden del sentido. El descubrimiento de Freud es el re-descubrimiento, en un terreno virgen, de la razón". ${ }^{31}$ Claramente es novedosa, en la medida en que la razón que nacía a principios de siglo XIX, si bien se vislumbraba en la lógica aristotélica, no era fácil de ser aceptada. Sin embargo, como se expuso inicialmente, quien prestó atención a esta otra razón mediante las posibilidades de acceso que posibilitaba el método indiciario y posterior estructuración lógica, fue Freud.

Así, el psicoanálisis articula algunas nociones, conceptos y métodos (cercanos o lejanos de la ciencia), pudiendo encontrar un lugar entre los cuerpos de saber y prácticas de Occidente, si bien con otro tipo de pretensiones obtenidas por vía del paradigma indiciario. A Freud, como consecuencia, el uso de esta metodología le trajo problemas desde su inicio como investigador, llegando a conocer muy bien a qué debía atenerse quien deseara formar parte de la causa psicoanalítica. En primera instancia, el éxito en la universidad se vería coartado. En el discurso universitario no hay cabida para lo inesperado, para lo transgresor del método, sino para la conservación del mismo en virtud de una producción masiva y uni-forme de profesionales. En segunda instancia, si hubiera de entrar en la vida como médico practicante, se encontraría en medio de una sociedad que no comprende sus empeños, que lo mira con desconfianza, con hostilidad, y que le suelta todos los malos espíritus que en ella están en acecho. En efecto, todavía en la actualidad se puede apreciar la hostilidad frente al discurso psicoanalítico de parte de la medicina, la psiquiatría organicista, e incluso, una gran parte de la psicología.

En ese orden de ideas, la cuestión que continúa resonando es por la prevalencia entre las diferentes formas de investigar, de tratar y dar respuesta al padecimiento humano. Las formas tradicionales tratan de imponerse y de erradicar a las alternativas. Sin embargo, no lo consiguen del todo, quizás por los impases de las "científicas" o por la eficacia de las alternativas. Ante esta situación, Élisabeth Roudinesco afirma: "Durante dos siglos, todas las políticas llamadas de 'salud pública' permitieron que la medicina científica

${ }^{31}$ Lacan, J., El seminario. Libro 1: Los escritos técnicos de Freud, p. 14. 
afirmara su superioridad sobre todas las otras terapéuticas -mágicas, culturales, esotéricas- sin haber logrado erradicarlas nunca". ${ }^{32}$

\section{Conclusión}

Lo elaborado en el presente trabajo, creemos, permite entender el método adoptado por Freud como derivado del paradigma indiciario, método que no era propio de la ciencia, aunque ésta se pueda servir de él. En esa dirección se puso en tela de juicio a la ciencia y su método, demostrando los agujeros que la modernidad se ha encargado de hacer evidentes por vía de la filosofía, la física, la matemática, la lógica, entre otras disciplinas. Esto mismo permite situar al psicoanálisis, no respecto de las pretensiones científicas, sino como un cuerpo de saber en extensión, con una eficacia, una metodología, y una práctica que suscitan continuamente una interrogación del sujeto por la verdad.

Empero, no es nuestra finalidad exponer al psicoanálisis o su método como infalible, ni convencer a quien prefiera la base sólida de los cuerpos orgánicos o la creencia en el proyecto científico como un todo. Lo que se pretendió fue exponer otro método que, pese a no ser el hegemónico, no se vuelve por ello menos eficaz. Simplemente sirve a otros fines, otras problemáticas, y otras formas de acceder a lo que el primero -el método científico- se encuentra como impase. Igualmente, se pretendió exponer el paradigma indiciario y su uso en la teoría psicoanalítica, no como un acontecimiento histórico sepultado, sino como un marco epistemológico en devenir que permite pensar y cuestionar al universo de las ciencias. Esto siempre en la soldadura de la teoría, la investigación y la clínica.

Podrán surgir estudios más exhaustivos en lo concerniente a las formaciones del inconsciente, donde se puedan abordar éstas en mayor proporción, ya que sólo se hizo uso de algunos ejemplos en su confrontación con el proceder de Freud. Para posteriores reflexiones se puede someter a análisis, incluso, la casuística de éste: esos historiales que aún continúan siendo debate en el argot psicoanalítico. También se podrá disponer del paradigma en cuestión para abordar las intelecciones de Lacan, que tuvieron

32 Roudinesco, Élisabeth, El paciente, el terapeuta y el Estado. Buenos Aires, Siglo XXI, 2005, p. 27. 
la necesidad de buscar amparo en los avances del movimiento científico de su época. En todo caso, lo que implica el horizonte con que se deberá lidiar es el continuo fracaso en la aprehensión de la escurridiza verdad o realidad, verdad o realidad para la cual el actual es un discurso más.

\section{Bibliografía}

- Bleichmar, Silvia, La construcción del sujeto ético. Buenos Aires, Paidós, 2011.

- Foucault, Michel, Nietzsche, Frend, Marx, Buenos Aires, El cielo por asalto, 1964.

- Freud, Sigmund, Conferencias de introducción al psicoanálisis (partes I y II), en Obras completas, edición de J. Strachey, traducción de J. L. Etcheverry y L. Wolfson, Vol. XV, Buenos Aires, Amorrortu, 1978.

- Freud, Sigmund, La interpretación de los sueños. Primera parte, en Obras completas, edición de J. Strachey, traducción de J. L. Etcheverry y L. Wolfson, Vol. IV, Buenos Aires, Amorrortu, 1979.

- Freud, Sigmund, Lo inconsciente, en Obras completas, edición de J. Strachey, traducción de J. L. Etcheverry y L. Wolfson, Vol. XIV, Buenos Aires, Amorrortu, 1984.

- Freud, Sigmund, El Moisés de Miguel Ángel, en Obras completas, edición de J. Strachey, traducción de J. L. Etcheverry y L. Wolfson, Vol. XIII, Buenos Aires, Amorrortu, 1986.

- Freud, Sigmund, Fragmentos de la correspondencia con Fliess, en Obras completas, edición de J. Strachey, traducción de J. L. Etcheverry y L. Wolfson, Vol. I, Buenos Aires, Amorrortu, 1986.

- Freud, Sigmund, Psicopatología de la vida cotidiana, en Obras completas, edición de J. Strachey, traducción de J. L. Etcheverry y L. Wolfson, Vol. VI, Buenos Aires, Amorrortu, 1986.

- Ginzburg, Carlo, Mitos, emblemas e indicios, Barcelona, Gedisa, 1989.

- Lacan, Jacques, "Breve discurso en la ORTF", en Intervenciones y textos 2, Buenos Aires, Manantial, 1988 [1966].

- Lacan, Jacques, El seminario. Libro 1: Los escritos técnicos de Freud, Buenos Aires, Paidós, 1981 [1953].

- Masotta, Oscar, Lecturas de psicoanálisis. Freud, Lacan, Buenos Aires, Paidós, 1992. 
- Pardo, Rubén, "Verdad e historicidad. El conocimiento científico y sus fracturas", en E. Díaz (Ed), La posciencia: el conocimiento cientifico en las postrimerías de la modernidad, Buenos Aires, Biblos. 2007, pp. 37-62.

- Poe, Edgar, "Los crímenes de la calle Morgue", en Cuentos, Puerto Rico, Universidad de Puerto Rico, 1956.

- Prigogine, Ilya, El fin de las certidumbres, Santiago de Chile, Editorial Andrés Bello, 1997.

- Roudinesco, Élisabeth, El paciente, el terapenta y el Estado. Buenos Aires, Siglo XXI, 2005.

- Saussure, Ferdinad, Curso de lingüistica general, Buenos Aires, Editorial Losada, 1945.

- Vieytes, Rut, Metodología de la investigación en organizaciones, mercado y sociedad. Buenos Aires, Editorial de las ciencias, 2004.

Recibido: 02/2019. Aceptado: 08/2019. 